\title{
La tecno-comunicación: una moneda de tres lados
}

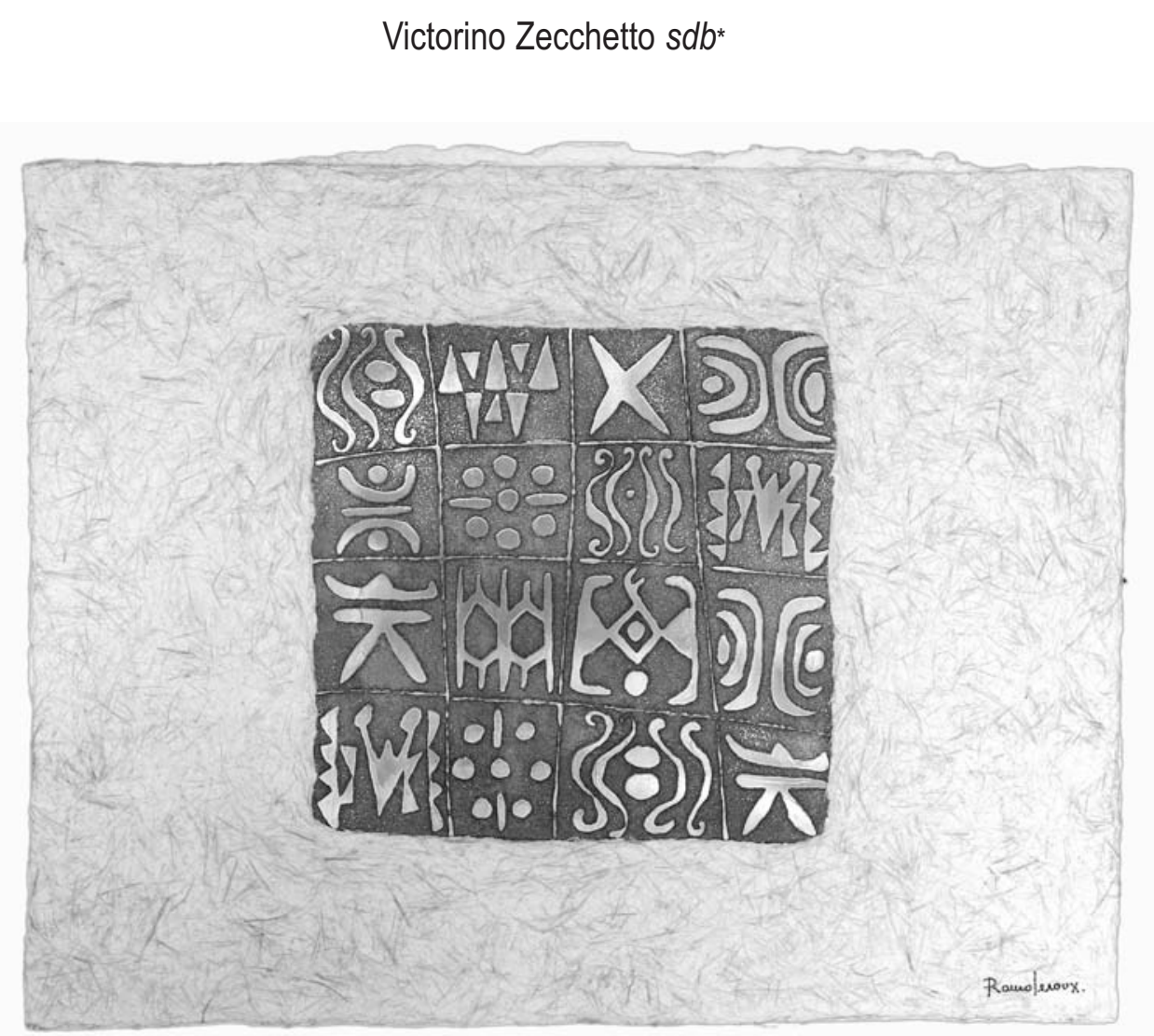

Traer la selva a la ciudad

El presente artículo pretende dar cuenta del fenómeno de la 'experiencias mediáticas' que nos proporcionan los medios de comunicación social y las nuevas tecnologías. Dado que las mutuas relaciones entre comunicación y tecnología tienen un evidente perfil 'interesado' - en el sentido que responden a un objetivo de carácter comercial- su funcionamiento se comprende a partir del diseño 'funcional-económico' que lo sustentan, y no sólo por las características de cada elemento tomado en forma independiente. Desde este ángulo, las proyecciones

* Profesor del Instituto de Comunicaciones Salesiano (COSAL) de Buenos Aires. Autor de diversos artículos y publicaciones de enseñanza universitaria sobre comunicación y semiótica. 
educativas y culturales que asumen las 'experiencias mediáticas', especialmente en los jóvenes, no pueden ser pensadas como algo neutral, sino que van asociadas a un abanico de 'responsabilidades ideológicas' repartidas en varios estamentos.

\section{La experiencia mediático-tec- nológica}

La tecnología comunicativa que utilizamos a diario, en la vida social, nos plantea el tema de la vinculación entre las 'experiencias humanas primarias' y las 'experiencias mediáticotecnológicas'.

Las experiencias llamadas tradicionalmente 'primarias' las constituyen los encuentros directos cara a cara con otras personas, en éstos prima la inmediatez de la palabra y el gesto. Acá los sentidos se expresan plenamente en el espacio-tiempo de la realidad física de los interlocutores presentes: un saludo, un abrazo, un beso, su voz y mi voz en diálogo directo, el ritmo y los tonos de las palabras, las risas, los silencios, las miradas, la vista del cuerpo, los modos de vestir, los aromas y los olores, el ritmo y el gesticular de brazos y manos, las expresiones del rostro, de los ojos, de la boca... Los pliegues complejos de las relaciones humanas primarias han sido ampliamente analizados por la psicología, por la cinésica, la proxémica y la etnografía -y mucho antespor el arte: la pintura, la escultura, el teatro, la literatura y la novela. Las gratificaciones que proporcionan estos encuentros primarios, revelan las raíces ancestrales antropológicas de la comunicación como parte esencial de nuestra estructura humana. Pero lo oscuro, es decir, el fracaso de la comunicación, pertenece igualmente a nuestra condición; la experiencia del dolor de la ruptura y del desencuentro, la hipocresía o la violencia, manifiestan el drama de la incomunicación. Tal vez a causa de esta triste realidad tienen tanto éxito las tecnologías de la comunicación, como un escape hacia zonas más apacibles.
Ellas han dado un vuelco a las relaciones humanas, porque han transformado la percepción que tiene el sujeto de sí mismo, su visión del entorno y del mundo. Este proceso se basa en la triple posición y logros conquistados por la tecnología: su gran potencial informativo a nivel planetario, con las repercusiones políticas, económicas y culturales que este hecho conlleva, el servicio prestado a la comunicación personalizada entre individuos ubicados a distancia en cualquier espacio y tiempo, y en tercer lugar, el ingreso de la tecnología a la esfera privada para funciones lúdicas solitarias, como es la fruición individual de música, de imágenes, de lecturas, de datos, de juegos...

A continuación distribuiremos en tres apartados algunas reflexiones sobre estas experiencias que se mezclan -a modo de una mermelada- y que le dan forma a las actuales comunicaciones.

\section{Sobre los rieles de la infor- mación}

El interés por la información se explica por la fuerza y la eficacia que ella tiene en todos los ámbitos de la vida social, económica, científica y cultural. El desarrollo de una nación o de un grupo social, depende del protagonismo que se le atorgue a los datos y a las informaciones para manejar cualquier campo de la actividad humana. El tren que viaja hacia la estación de nuevos progresos, de un mayor desarrollo social y de mejores niveles de vida, se desliza sobre los rieles de la información y de su correspondiente tecnología. La información en este caso asume dos modalidades, una es muy restringida y controlada, la otra en cambio es de circulación masiva dirigida a todo el mundo.

\section{a) La información restringida}

Está al servicio de las grandes transacciones financieras y movimientos económicos en- 
tre grupos selectos o poderosas empresas en cualquier parte del globo. La autopista mundial de la información permite la transferencia y apropiación ultra rápida de datos y conocimientos relativos a la economía y a los manejos bursátiles. Los países más ricos que disponen de recursos para promocionar las investigaciones científicas y tecnológicas, acaparan también la información más valiosa para sus intereses económicos. Los pueblos pobres viven de lo que esas naciones estén dispuestas a otorgarles, según les convenga, incluso en sectores tan indispensables como es la salud. En el año 2002, varios estados de África y otros continentes, consternados por la gran mortandad que producía el virus del sida, levantaron un pedido a la OMC (Organización Mundial del Comercio) para que aprobara un régimen de patentes que garantizara la protección de todas las innovaciones tecno-

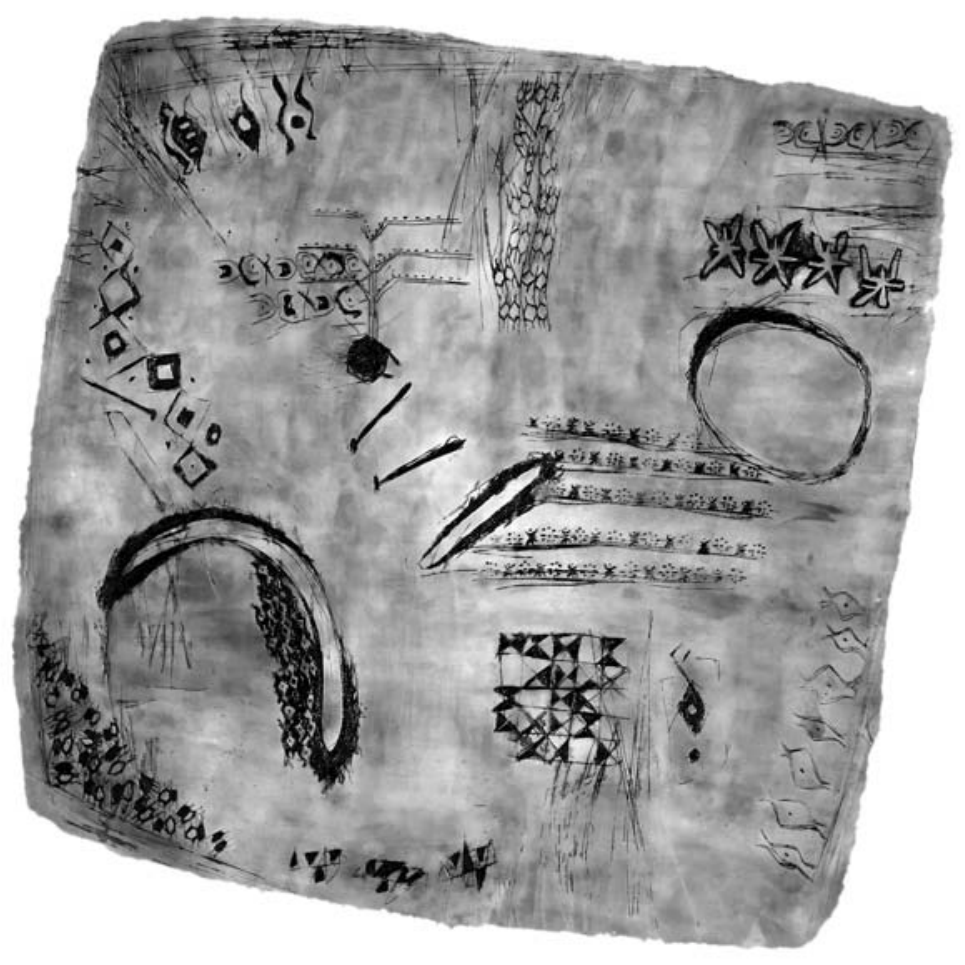

Sólo lo irreal puede perderse. Detalle lógicas, incluyendo los medicamentos empleados para combatir el VIH-Sida. Brasil con un volumen de 180 millones de habitantes, tomó la iniciativa de producir un genérico del Kaletra, un medicamento antirretroviral del Sida, cuya patente norteamericana encarecía enormemente el tratamiento de la enfermedad. La batalla legal fue dura y no fue fácil imponer razones humanitarias para que éstas prevalecieran por encima de los intereses económicos.

Las innovaciones tecnológicas concernientes a ciertas áreas claves del desarrollo y del dominio económico, militar o científico, son celosamente custodiadas y su difusión es estrictamente controlada por los países que las poseen. La alta tecnología satelital de las comunicaciones es una de ellas. En el área de las TICs (Tecnologías de la Información y de las Comunicaciones) se investiga y desarrolla los sistemas de satélites, los de simulación, el análisis y la gestión de información de micro y nanomateriales, módulos bioinformáticos y otros diseños de alta tecnología de la informática avanzada. Está claro que la investigación y la fabricación de sofisticados satélites y otras maquinarias requiere de cuantiosos recursos que sólo pocas naciones poseen. Lo deseable sería que, al menos, esas investigaciones científicas no fuesen militarizadas, sin embargo se sabe que existe una muy sofisticada tecnología aplicada al armamento y a todo el aparato de información militar de la guerra, como también al espionaje donde se utilizan aparatos e instrumentos extraordinariamente desarrollados ${ }^{1}$.

\section{b) La información con destino masivo}

Tiene que ver con la información manejada por los megagrupos nacionales y transnacionales de las comunicaciones que operan por el mundo entero ${ }^{2}$. 
Los Estados - una vez que se han reservado el control de la indispensable información estratégica- entregan el resto a la 'desregularización', es decir, abandonan el control directo de las informaciones y comunicaciones públicas para favorecer el crecimiento de las empresas privadas y la economía de libre mercado. El Estado liberal se limita a fijar un ordenamiento jurídico básico para el área y la actividad informativa. Sabe que las innovaciones tecnológicas y sus aplicaciones dependen estrechamente de las inversiones económicas, sobre todo, de las que provienen de los centros con poder financiero. La transnacionalización de las comunicaciones se ha convertido en el modo ordinario de operar. No extraña, entonces, que asistamos a frecuentes megafusiones y al surgimiento de megagrupos de comunicación, que afectan a millones de personas a través del mundo.

Mientras las naciones avanzadas son muy avaras para proporcionar a los países pobres alta tecnología e información útil, demuestran gran generosidad en venderles la tecnología que facilita el consumo de sus productos. La industria de 'hardware' y 'software' está dirigida a las empresas de comunicaciones que operan tanto a nivel nacional como continental, y sin el oculto propósito de internacionalizar el mercado favoreciendo la concentración de los medios en pocas manos. Los 'holding de las comunicaciones' poseen capacidad para invertir, con altos costos iniciales, en la compra de los complejos tecnológicos y comerciales que demanda la industria mediática. Pero las consecuencias las pagan los ciudadanos. Los medios de comunicación antes considerados 'bienes de interés público' (que no significa 'interés estatal') como la radio y la televisión, ahora dependen de entidades privadas que los manejan según la estricta ley del marketing, lo cual implica impulsar una maciza acción de rendimiento económico por encima de cualquier otro valor social. No es de extrañar que 'la información' de interés público se convierta en 'espectáculo cruzado', donde confluyen publicidad, teatralidad, sensacionalismo y otros adornos para la venta comercial de productos y de informaciones a menudo banales que no proporcionan a los ciudadanos aquellos datos importantes para conocer y discernir el desarrollo de la vida social y política. Resulta cada vez más difícil distinguir entre noticias importantes y las insignificantes o irrelevantes. Constatamos que, por un lado, el caudal informativo es asombroso, porque la cantidad absoluta de información crece a nivel planetario, mientras que por el otro no está nada claro si contemporáneamente se expande también el grado de comprensión relativa de dicha información en cada individuo. Sabemos que la manipulación informativa abunda. Con la aceleración del crecimiento de las informaciones, se acorta también el tiempo de envejecimiento de éstas y su olvido. Fácilmente sus contenidos se tornan poco novedosos, inútiles y no actuales, de modo que los grandes medios masivos, al necesitar cada vez más nuevas informaciones, gastan tiempo y dinero para captar la creciente marea informativa, mientras el gran público receptor, no posee la tranquilidad para hacer una mínima evaluación acerca de la calidad del material que ve, escucha y recibe. Con razón observa el crítico social Noam Chomsky: "Los hechos reales sólo pueden ser desenterrados si uno se aleja de los medios de comunicación más importantes".

Los medios de comunicación desempeñan también un rol tendiente a favorecer el 'consenso social' en torno a temas económico-sociales, políticos u otros asuntos candentes. El 'consenso' opera en la mente de los ciudadanos, pues los predispone a aceptar acuerdos o afirmaciones sin discutirlas. El consenso sirve para absorber el disentimiento, y se regula a través de 'lo obvio' impuesto desde la información y el tratamiento de los discursos sociales. Los ciudadanos aunados en el consenso aprecian el imaginario del 'orden', se autocensuran y evitan todo aquello que creen puede llevarlos al caos, ya que éste aparece como contrario a la 'integración social', factor necesario para disfrutar del orden. Sobre todo es el capitalismo de consumo el que más se beneficia con el consenso, porque produce la 
sensación de ver realizadas las aspiraciones del promedio de la población ${ }^{3}$. En este terreno de la persuasión y del consenso funciona igualmente la mercadotecnia política que es eminentemente masiva ${ }^{4}$. Episodios sonantes de manipulación informativa los vemos en toda América Latina. Recientemente en Venezuela y Argentina algunos han asumido ribetes trági-cómicos, pero en cada caso con modalidades opuestas. En Venezuela, el presidente Hugo Chávez (aquí no juzgamos sus logros sociales en beneficio de los sectores más pobres del país, sino únicamente el aspecto de la 'comunicación') 'copa la televisión', se convierte en vedette político y en showman de espectáculos musicales. En Argentina, el presidente Néstor Kirchner jamás dio una conferencia de prensa a lo largo de todo su mandato de cuatro años, sin embargo, se enfrentó repetidamente a los medios y al mismo tiempo los mantuvo a raya cautivándolos con dádivas. En muchos países, llamados 'democráticos', es así como funcionan los medios de comunicación, donde todos son amigos de todos, y desde arriba o desde los costados los profesionales de la comunicación se guían por el 'delirio del mutuo control'. Bien podemos aplicar acá la frase de un poeta pensador: "Va a llegar el día en que no vamos a saber qué es la locura"5.

En el ámbito educativo resulta muy formativo usar la tecnología con creatividad e inteligencia, teniendo en cuenta que hoy los instrumentos pueden ser manejados con gran iniciativa personal, lo cual permite coordinar su uso para promocionar visiones más críticas de la realidad. Es preciso advertir, sin embargo, que aunque las técnicas de información y de comunicación favorecen la educación individualizada, no escapan al peligro de aislar socialmente, en detrimento de la comunicación espontánea y de la observación recíproca. La educación debe sin duda tecnificarse cada vez más, pero sin abandonar las funciones de socialización y relación social ${ }^{6}$.

\section{Los deseos de la gente común}

A pesar de lo dicho en el párrafo anterior, descartamos la idea de que los medios de comunicación, por sí mismos, influyen de manera determinista en la gente de modo que ésta recibiría pasivamente sus mensajes. Existe más bien una connivencia cultural, a menudo tácita, entre el público y los medios, porque ambos viven inmersos en un mismo mundo. Pero lo esencial y para nada marginal, es el deseo que tiene toda persona de comunicarse, de manera que podemos concebir los instrumentos de comunicación como los portadores de 'una función vicaria comunicativa' cuyas raíces están en cada ser humano.

En América Latina, al igual que en otras partes del mundo, la televisión es todavía el medio más socializador y ocupa un lugar central en los hogares como instrumento de información y de entretenimiento familiar. Mirando la televisión en América Latina no se ven grandes diferencias entre las ofertas de un canal de España, Filipinas, China o Europa. Las formas y los contenidos son similares prácticamente en todo el mundo. Las telenovelas brasileñas las miran en Lima, pero también en Lisboa, en Varsovia, y en Moscú. Lo mismo sucede con las noticias provenientes de las agencias internacionales. En todas las cadenas se hallan contenidos similares: informativos, espectáculos musicales, concursos, series...

Hace algunas décadas se discutió en los ámbitos académicos acerca del rol de los medios en la estructuración de la identidad social. Los resultados de esas investigaciones no han sido uniformes. La tendencia fue considerar la identidad individual (sobre la cual se basa en parte también la social), tejida en torno a tres ejes: el 'ser nacional', el 'mercado compartido' (el consumo) y los 'medios de comunicación social'. En estos momentos, estos tres pilares -al menos en nuestro continente- ya no parecen unificar a los ciudadanos, debido a la enorme asimetría con que son vividos por millones de latinoamericanos que experimentan la ruptura de su ser en relación con esos componentes, y sufren la profun- 
da sensación de sentirse extraños a sí mismos. El 'ser nacional' (más allá de lo meramente folklórico), se arrastra a la deriva por los golpes que recibe de poderes ajenos a los intereses comunes de los ciudadanos. Dentro de un mismo país está el primer y el cuarto mundo, pero los más numerosos son los desamparados, mientras el Estado nacional es un discapacitado impotente y con muy poco control para mejorar la situación. Domina el 'mercado globalizado', sus productos y el consumo de bienes. En América Latina lo más globalizado, sin embargo, ha sido la pobreza que empuja a miles de personas a emigrar hacia países más ricos en busca de nuevas oportunidades. En el 2001, los latinoamericanos en el extranjero enviaron a los familiares de su país de origen, millones de dólares, lo equivalente a una vez y media de todo el dinero que pagó América Latina ese año en concepto de deuda externa ${ }^{7}$.

En este contexto los medios de comunicación también han sido globalizados y transmiten una cultura transnacional. Abundan los relatos del 'dios mercado' y de la política contra el terrorismo, que, actualmente, aparece como primordial y debiera ser la que cohesiona socialmente el mundo occidental. Pero estos relatos no son narrados de cualquier manera, sino que su acción se organiza con acercamientos diversos, por ejemplo, bajo forma de 'democracia de la inmediatez' en la escena política, o bien, con estilo de entretenimiento mediático, a pesar de la desigualdad informativa y tecnológica entre países centrales y periféricos. Un botón de muestra: en lo que va de esta primera década del siglo XXI, cerca del 90\% de los beneficios producidos por el cine, la radio y la televisión se lo llevan cinco empresas holding de nuestro continente, empresas globalizadas que controlan y venden el idioma internacional de los audiovisuales. Al iniciar el siglo XXI, el 87\% de las importaciones audiovisuales que recibía

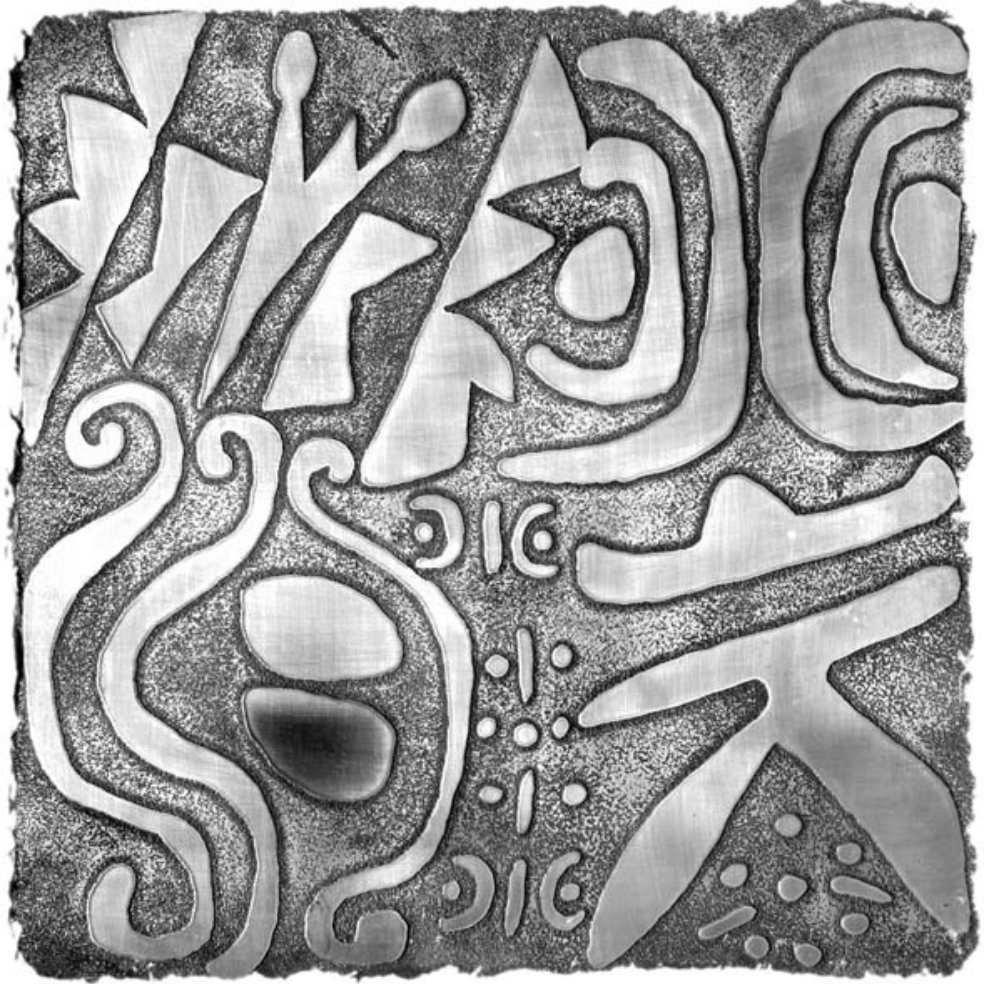

Tenemos derecho a la paz. Detalle

América Latina, provenían de Estados Unidos, el $6 \%$ de Europa y el 5\% de la propia región. Otros datos de la UNESCO confirman la misma situación hasta el presente ${ }^{8}$.

Con el paso del tiempo la tecnología nos ha entregado nuevas potencialidades de comunicación tanto interpersonales como grupales. En la actualidad están bien asentadas las 'tecnologías sociales', esto es, aquellas herramientas basadas en la Internet que permiten y facilitan las relaciones entre los usuarios, y crear o tejer redes sociales múltiples.

El enorme auge y la rápida expansión que ha tenido la telefonía celular son claros testimonios de esto. Numerosas encuestas revelan que el uso más frecuente del celular no es por razones laborales, sino para intercambiar bromas, saludos, amores y chismes. Prosperan las ganas de enviar y recibir mensajes cifrados, experimentar 


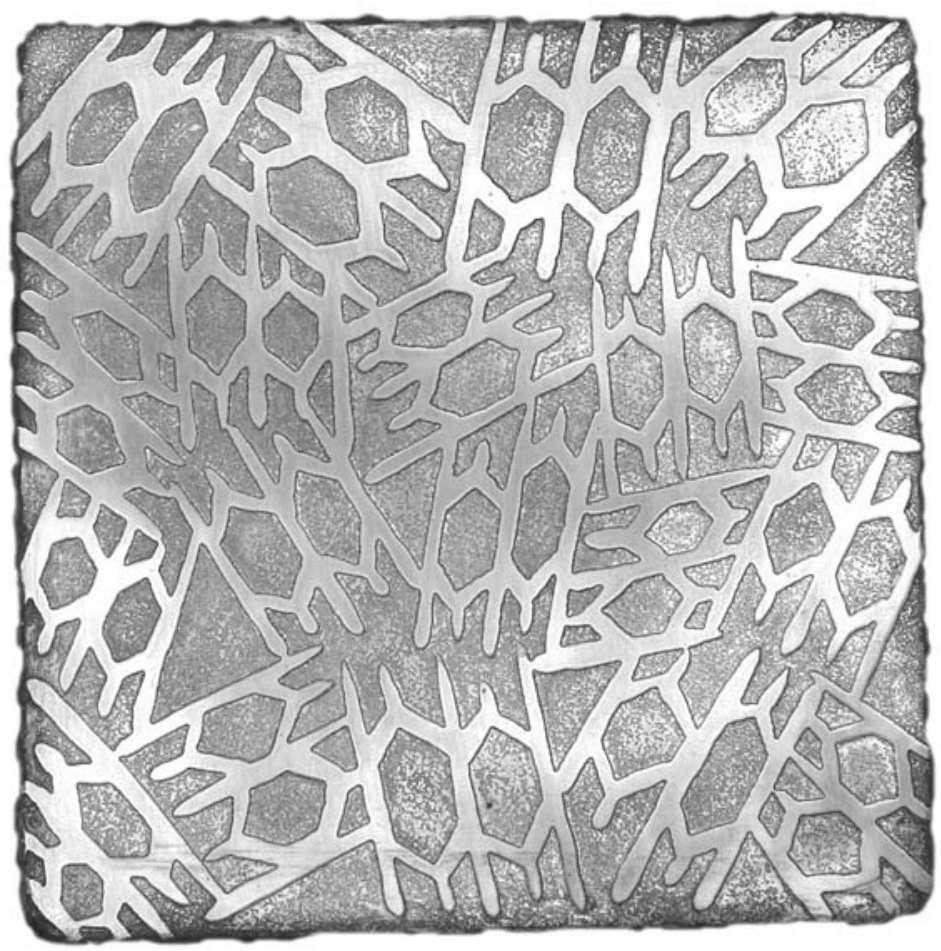

Ofidios. Detalle

encontrado plagada de millones de personas escribiéndose, mandándose mensajes de 'sms', hablando y conversando.

Las 'páginas web' con su arquitectura de hipervínculos, abierta al mundo y con infinitas modalidades de contactos con personas. Los 'weblog' han adquirido gran popularidad por su potencial participativo; muchas personas ven realizado su deseo de compartir o enfrentar con otros ideas, informaciones, sentimientos, opiniones.

Según estudios sobre las TICs en lo que respecta a Internet, la mayoría de usuarios se conectan en sus casas o en el trabajo, para cubrir diversas expectativas: desde la búsqueda de información de calidad (con fines laborales o educativos), hasta descargar melodías.

Las discusiones de grupo y los foros con participación de sectores sociales, permiten a los usuarios tomar contactos a distancia, conectarse y acceder a datos y a informaciones de enorme interés para su formación personal o su vida profesional. En el sector educativo

el encanto de lanzar o de atrapar esos 'papelitos' electrónicos que llenan nuestras soledades. Es en este contexto que debemos comprender las tecnologías de la comunicación, de modo especial 'Internet' y las situaciones comunicativas que pone a nuestra disposición en el intercambio con los demás, sobre todo las siguientes.

El Correo Electrónico con sus diversos formatos: mensajes epistolares personales y/o coloquiales, misivas estándares, instrucciones formales de carácter profesional o institucional, los 'chat' y las notas de 'ciberchismes'. Los sistemas de mensajería instantánea dieron origen a comunidades o grupos con espacio propio para relacionarse entre ellos. En suma, el Correo-electrónico constituye uno de los canales de conversación más apreciados de la tecnología digital, y de mayor incidencia transformadora de la actividad epistolar tradicional. En poco tiempo la red se ha hay padres y docentes que están preocupados por el aumento de las relaciones virtuales en detrimento de las 'presenciales'. Creemos que por el momento, no es este un grave problema en América Latina, pero ciertamente habrá que tenerlo en cuenta en el futuro.

La vía digital permite seleccionar el área individual o el área de participación grupal ${ }^{9}$. En la práctica la línea divisoria entre ambos espacios es tenue por el constante flujo y tráfico que circula en la Internet y que empuja a los individuos a lanzarse al ciberespacio con pasión. No está dicho, sin embargo, que la experiencia navegante realice una mayor interconexión social. Desde el módulo personal de la computadora, los ciudadanos ise comunican más o viven más aislados e independientes? Pareciera que la convergencia en los multimedia no llena la separación espacial de gente que por cierto, sigue de- 
seando comunicarse, pero sin verse las caras con su presencia física.

\section{El territorio individual}

Por último, el otro ámbito donde se cristaliza la experiencia mediática es el del territorio individual y privado. Desde su encierro y cara a cara con el medio, el individuo accede a la libertad del 'disfrute en conexión', pudiendo atravesar múltiples niveles de vivencias y de situaciones, a través de la interacción tecnológica. Esta actividad en solitario ha transformado ya los hábitos de comunicación de miles de personas que, bajo los efectos de la tecnología, encaran el mundo y las relaciones humanas, a impulsos constantes de la Internet.

De pronto en los jóvenes, la experiencia estudiantil basada en el uso de la Internet, afecta el modo de proyectar y orientar el estudio personal. La apropiación de conocimientos, la reducción de tiempo en la búsqueda de informaciones de calidad, la eficacia en la realización de los trabajos, da lugar a otra forma de aprendizaje y además produce la satisfacción de conservar el control sobre la propia formación profesional. Así también la actividad laboral, profesional o empresarial basada en el sistema informático, opera en forma multidireccional logrando crear modelos más perfeccionados de empresas y servicios.

Acá, sin embargo, nos interesa detenernos solamente en dos unidades experienciales acotadas a la forma individual del uso tecnológico. Primero apuntamos a la experiencia que se construye en el mundo virtual en general; la segunda visualiza el entretenimiento a través de los videojuegos.

\section{La experiencia virtual}

Entre la pluralidad de experiencias comunicativas la 'realidad virtual' ocupa un lugar curioso por la perspectiva que representa. Analicemos brevemente este fenómeno.
Como sabemos, la imagen no es la realidad que ella significa, tan sólo es su representación. En cambio es real la imagen misma. A veces hay sujetos que confunden la imagen con el referente cuando aquélla posee un alto grado de iconicidad. Las actuales tecnologías sofisticadas van produciendo un cambio fundamental en las imágenes, porque les crean nuevos soportes o superficies. Ya no de papel, de película o de otro material, sino imágenes digitales electrónicas. De allí surge la 'realidad virtual'; es decir, la reconstrucción computarizada de las cosas y de los ambientes, con variadas maneras de administrarlas. Lo característico de la técnica virtual, es que crea un ámbito de 'simulación' de la realidad, modelándola en forma puramente simbólica mediante señales numéricas digitales. Los objetos representados en las imágenes virtuales aparecen tridimensionales, y se ven como figuras idénticas a las reales. Hoy, la tecnología virtual, se aplica a muchísimos campos de la vida humana y social, $y$ es una herramienta para obtener importante conocimiento e información en medicina, en arquitectura, en organización ambiental, en aviación civil, en capacitación profesional, en agricultura, en ecología y, por supuesto, también en los juegos y en recreación.

Los usuarios que vivencian situaciones virtuales se sienten transportados en un mundo de realismo impresionante y original. La simulación virtual, sumerge a los individuos dentro de la realidad, sin que ésta, sin embargo, sea verdadera. Se trata de una seudo-realidad, de una mediación entre lo que de es real y su modelo representado con entornos tridimensionales modulados. También las posturas del cuerpo y los gestos participan de la inmersión en el mundo virtual, donde las distancias, los espacios, los lugares y los tiempos son programados con absoluta fidelidad al entorno real. Las imágenes virtuales nos proporcionan un tipo de visibilidad y movilidad distinto del común. Es una iconografía casi inmaterial que instaura un tipo de presencia y de comunicación distintas. La sensación que se tiene es como la de vivir junto o dentro de objetos 
reales: correr sobre una ruta, viajar dentro de un submarino, o conducir un avión por el cielo. En esos casos, se experimentan agudas emociones por el impresionante realismo que brinda la realidad virtual y sus alucinantes imágenes.

El peligro en el que se puede caer -numerosos hechos de crónica así lo confirman igual como pasa ahora con la televisión, pero a un nivel más profundo- consiste en confundir los fenómenos del mundo virtual con la realidad. Los seres humanos tenemos una asombrosa capacidad de invertir las cosas, porque soñar no cuesta nada.

En la experiencia virtual, la fuerza 'vicaria' de los sonidos, de las imágenes, nos colocan, pues, en un escenario que bien puede quedar encerrado en sí mismo (individualismo experiencial puro), o bien abierto a una nueva colectividad, hacia horizontes geográficos de navegación planetaria, en contacto y en redes más universales, que despiertan la conciencia de pertenencia al mundo globalizado en acciones comunes de solidaridad. Del punto de vista educativo, este enfoque reivindica la necesidad de definir métodos y usos de lo virtual, a fin de que su aplicación apunte a modos y formas de vida que incorporen las diversas facetas del vivir diario, donde se articule lo personal con lo social; lo subjetivo con los problemas socio-político-económicos; lo privado con los intereses grupales, sin excluir los temas trascendentales acerca del significado de la existencia. Esto quiere decir que la experiencia virtual ha de colocarse dentro de modelos de desarrollo y crecimiento que no miren únicamente lo tecnológico, sino que abarquen lo más posible la realidad completa del ser humano. Son reveladores los testimonios de los usuarios comunes que, al entrar en contacto con las nuevas tecnologías virtuales, perciben no sólo sus asombrosas potencialidades, sino también las incógnitas que presentan para las relaciones interpersonales. Abriendo una página web al azar me encontré con el comentario de un lector al respecto: 'No se trata de cambiar un mundo por otro. Ni el tacto real, la experiencia directa o el apacible silencio por el contacto virtual y el ruido desatado. Se trataría más bien de aprender a navegar en un mar mucho más ancho, promisorio, y también embravecido del que hasta ahora teníamos noticia. La expansión del espacio -alcance universal de nuestro sitio en el mundo-y la aparente disolución del tiempo en la instantaneidad en la que sucede todo -quiebra de la distancia para la reflexión- nos deja boquiabiertos. No es para menos. Nos coloca ante nuevos retos que van a poner a prueba nuestra inteligencia emocional para relacionarnos bien con nosotros y con mucha más gente distinta con la que vamos a tener que tratar en todo momento'.

Apuntar al uso educativo del ciberespacio e implementar estrategias virtuales, es una tarea que se está empezando a desarrollar ${ }^{10}$.

\section{Las máquinas del yo absoluto}

La tecnología digital ha creado los videojuegos y los reproductores de música (en todas sus variantes y los 'gadgets' que los acompañan), que se han afirmado como un fenómeno mundial de contundente vigor. Gobernar por sí mismo o adaptar (hasta ciertos límites) esas tecnologías, concede al individuo una sensación de gran poder y autonomía. Uno aparece el dueño de las propias opciones. Es curioso observar que los más conspicuos inventores de videojuegos, son científicos que primero se aplicaron al estudio de la inteligencia artificial. Adam Russell, por ejemplo, es un programador de videojuegos, y crea sus programas como un desafío personal a los jugadores con complejas combinaciones lúdicas y sutiles variantes, por eso afirma: "Sólo hay una inteligencia verdadera en el mundo de los juegos en solitario: el jugador"11.

Con la música en cambio, nos trasladamos al pleno disfrute individual y libre, aislados de cualquier entorno incómodo. Tras el éxito de la primera generación de 'iPod', de continuo se perfeccionan las ofertas. El 'Napser Mobile' (que pronto será compatible con los 'iPod') ofrece 
hasta cinco millones de canciones. El diseño del reproductor MP3iPod de Apple es el símbolo de modernidad para los jóvenes. Si a esto le agregamos el 'iBuddy y Spin' tenemos consolas que permiten "hacer música a tu manera" (¡incomparable sueño juvenil!). No es casualidad que precisamente en el 2007 el Premio Nobel de Física haya sido otorgado a dos investigadores -Albert Fert y Peter Gruenberg- que lograron obtener un disco duro muy pequeño aplicable a computadoras y hasta a los 'iPod'. Estos científicos estudiaron los fenómenos de la "espintrónica" relativos a los electrones para almacenar y transportar información, y que están en la base de los continuos perfeccionamientos de los reproductores de sonidos.

El éxito del consumo de las 'tecnologías individuales' no se explica sólo por las ventajas y los refinamientos que ellas aportan, se trata de la configuración cultural en la cual están insertas, es una respuesta a otra demanda, que supera la homogeneización de gustos, y se concentra, en cambio, en la afirmación del espacio privado y personal, en la constitución de la propia subjetividad que se manifiesta -entre otras expresionesa través de los juegos solitarios y en la escucha individual de música.

Vistas así, estas tecnologías de disfrute privado, representan una revancha o rebelión -sobre todo de los jóvenes (víctimas y protagonistas al mismo tiempo)- hacia un mundo mal configurado. La prepotente expansión de los videojuegos y de los reproductores de música, no es puramente una cuestión económica, debe ser interpretada también como un fenómeno de 'postmodernidad', esto es, como la ruptura de un modelo de vivir. Algunos filósofos al analizar la 'postmodernidad' se preguntaron: ¿cuál es el espíritu de la cultura 'postmoderna' que invade a grandes masas de hombres y mujeres del mundo occidental urbano, incluyendo nuestra América Latina?

Ante todo se trata de un espíritu y de una cultura que no cree ya en los grandes proyectos sociales, es decir, en aquellos ideales o utopías ca- paces de construir una sociedad más igualitaria y fraterna ${ }^{12}$. La gente se repliega sobre sí misma, busca disfrutar del presente sin pensar mucho en el futuro. La vida se vive fragmentariamente, en una cotidianidad irrelevante, sin un pensamiento fuerte que contenga grandes proyectos, ni la búsqueda de elevados valores personales o sociales ${ }^{13}$.

El individuo ahora se pone como centro de todo. Predomina lo subjetivo, interesa la vida privada y lo que ella puede aportar al sujeto. Se aprecia el consumo, 'lo que me gusta, lo que yo siento.' Importa mi éxito personal, la creatividad en mi vida. Se rechazan los valores absolutos, las normas objetivas, las conductas éticas las define cada persona, 'todo vale' es el lema de base, de modo que los compromisos definitivos no tienen cabida. En cambio se quiere la libertad de cada día, las ideas personales, la felicidad en el presente y hacer valer los derechos individuales sobre cualquier otra cosa.

El modelo comunicacional configurado sobre las nuevas tecnologías posee algunas característicos que lo asimilan al estilo postmoderno. Primero es una comunicación de 'sinergia espacio-temporal', es decir, de aceleración informática y con ubicuidad a nivel planetario y en tiempo real. Ello crea la sensación de un 'mundo en fuga' que siempre corre hacia delante, hacia el futuro, desde un presente precario y volátil. Por eso -y esta es la segunda característica- las comunicaciones sociales operan a modo de verdades fluidas, son sólo 'casi verdades', son unidades culturales efímeras (modas, opiniones, símbolos, creencias, reglas...), hay exaltación de lo banal y de la crueldad. Resulta muy difícil saber si un acontecimiento posee una contextura histórica duradera y fuerte, o bien si se trata de algo que pronto se va a desarmar sin dejar huellas en la sociedad. En consecuencia, los múltiples productos inmateriales de la comunicación tiran sus residuos semióticos en forma de ideología. ¿Qué quiere decir, entonces, ser originales hoy, por más instrumentos personalizados que poseemos? ¿Detrás de qué identidad corremos? 
Por último, la información que recorre el mundo es capitalizada por la globalización y el poder económico. Esto hace que los 'nuevos relatos' manifiesten más los vaivenes del mercado, que un pensamiento consistente y abierto a la comprensión de la historia. El corolario es la pérdida del significado de la propia historia y de la orientación de la acción social.
La educación apunta a que los sujetos tomen en sus manos la propia libertad para fines constructivos. En la medida que la persona asuma actitudes responsables, será capaz también de enfrentarse con los discursos neo-tecnológicos para no caer en la trampa de otro totalitarismo ${ }^{14}$.

Buenos Aires, 2007

1 Noam Chomsky es uno de los estudiosos que más han profundizado este tema. Ver por ejemplo entre sus numerosas obras: Estados canallas: el imperio de la fuerza en los asuntos mundiales (2002) Edit. Paidós Ibérica; y Estados fallidos. El abuso del poder y el ataque a la democracia. (2007) ed. B

2 Sobre el asunto de las megafusiones léase los datos reportados en el artículo de Enrique Maza (2006): "Las megafusiones de la comunicación, el mundo bajo control", en: www.saladeprensa/org/art277htm

3 Resultó clarificador el best seller de divulgación escrito por N.Klein (2002): No logo. El poder de las marcas, Edit. Paidós, Barcelona. Un análisis más sociológico lo hace Zigmunt Bauman en: Trabajo, consumismo y nuevos pobres (2003), Edit. Gedisa, Barcelona.

4 Un estudio de la situación de la prensa mexicana lo realiza Ricardo Martínez M.: Medios de comunicación, ingeniería del consenso y periodismo en México (2004) www.rebelion.org/noticia.php? $\mathrm{d}=8345$

5 Un minucioso análisis de casos de descarada manipulación informativa protagonizadas en Italia por el magnate de los medios Silvio Berlusconi, la realiza en su obra Marco Travaglio: La scomparse dei fatti (2006, Il Saggiatore, Milano ), donde demuestra cómo las simples opiniones hacen desaparecer los hechos.

6 Interesantes 'consecuencias educativas' se deducen del estudio de Maritza López de la Roche: Representaciones sociales por audiencias infantiles, a partir del análisis de las 'mediaciones' ejercidas por los medios y tecnologías de la comunicación. En: Florencia Saintout / Natalia Ferrante (comp.): ¿Y la recepción? Balance crítico de los estudios sobre el público - Edit. La Crujía, Buenos Aires, 2006.

7 Los estudios sobre la migración latinoamericana no permiten aún dar un juicio definitivo sobre su significación socio-económica-cultural total. Es pertinente, sin embargo, citar como ejemplo, la investigación de José Dionisio Vázquez V. (2006) sobre una región de México de gran migración hacia Estados Unidos, estudio acompañado de una rica bibliografía complementaria: "La migración internacional como estrategia de reproducción familiar en la región oriental de Tlaxcala”. (Tesis doctoral).

8 Datos e informaciones de investigación empírica proporciona el estudio de Enrique Sánchez Ruiz (2006) de la Universidad de Guadalajara: "Industrias culturales, diversidad y pluralismo en América Latina”, en Gobal Media Journal. www.gmje.mty.items.mx/sanchez_ruiz.himl

9 Un amplio panorama del 'diseño comunicacional' creado por Internet lo presenta Manuel Castells (2002): "La galaxia Internet. Reflexiones sobre Internet, empresa y sociedad”, Debolsillo, Barcelona.

10 Ver: Unigarro Gutiérrez (2004): Encuentro formativo en el ciberespacio. UNAB - Colombia.

11 Www.meristation.com (6 julio/2005): La inteligencia artificial vista por Adam Russell (Entrevista).

12 La extrañeza de tanta gente por las propuestas de H. Chávez en Venezuela, que propugna una sociedad con ideales marxistas, me parece que se explica por este motivo: ¿cómo volver a publicitar hoy un ideario social de tipo marxista en una sociedad que ha barrido los proyectos universales y sólo le interesa lo individual?

13 Una reciente tesis del investigador del MIT Henry Jenkins (2007) Cultura convergente, sostiene que para rescatar a la gente de su desdén por la política, es preciso que los políticos imiten simplemente los lenguajes del consumo cultural mediático. Pero esta es, precisamente, la crítica dirigida a la muchos políticos, la de adaptarse sin criticidad, a los cambiantes y volátiles gustos de las mayorías.

14 La obra de Massimo Recalcati (2007): Forme contemporanee del totalitarismo (Bollati Boringhieri), sostiene que vivimos en un mundo de un nuevo totalitarismo sin saberlo, pero ya no el del 'Gran hermano' que nos espía, sino el de la ideología horizontal que nos llega de los objetos de entretenimiento. Se trataría de la transposición en clave mediática de la famosa 'biopolítica' de Michel Foucault. 


\title{
¿Qué hay detrás de la palabra?
}

\author{
Ensayo para la inconformidad
}

Jaime Torres*

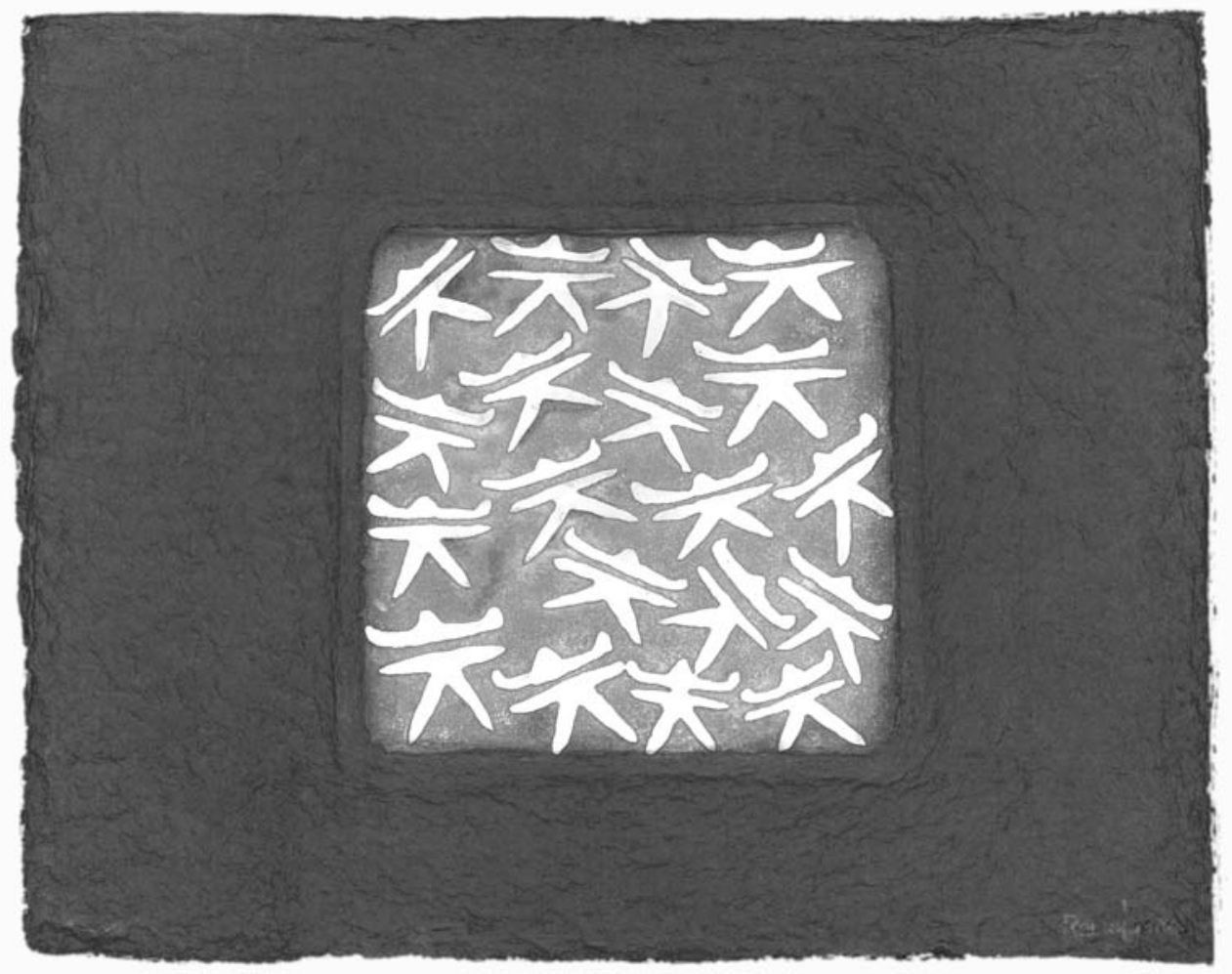

Mariposas nocturnas

El valor, sentido, uso y significado que tiene la palabra pueden ser ubicados en un escenario multidireccional: en el plano de lo real o en el plano de lo simbólico; en el uso práctico o en la imaginación; en el hacer y en el desear. La palabra nos ha conducido en la historia por el misticismo (la magia), por la verdad de las cosas (la ciencia), por ello es que nos provoca inquietud y nos atrae; toda palabra genera sospecha, sorprende, domina, ilusiona, entristece y libera; sin ella no podemos existir en el mundo, ni tampoco dar cuenta que caminamos en él, y sin su presencia no podríamos transformarlo.

* Doctor en psicología clínica por la Universidad Central del Ecuador y profesor de las Carreras de Comunicación Social y Psicología de la UPS - Quito. 